\title{
ANTROPOLOGIA DA IMAGEM NO BRASIL: EXPERIÊNCIAS FUNDACIONAIS PARA A CONSTRUÇÃO DE UMA COMUNIDADE INTERPRETATIVA
}

\author{
Cornelia Eckert ${ }^{1}$ \\ Ana Luiza Carvalho da Rocha ${ }^{2}$
}

\section{Introdução}

A Antropologia como campo de produção de conhecimento científico se consolidou na civilização ocidental como uma disciplina predominantemente escrita. As imagens e os sons, durante boa parte do século XX, desempenharam o papel de "anexo" ou de "ilustração" nas pesquisas antropológicas. Usadas como testemunho do "eu estive lá” (Geertz, 2005) por parte dos antropólogos, a produção audiovisual resulta do trabalho de campo objetivando a experiência etnográfica da alteridade radical (Peirano, 2006: 58) de observação e escuta do "nativo" em seu contexto vivido. Nestes contextos da materialidade ou a grafia de sons e visualidades implicava recolher dados etnográficos como patrimônio tangível das evidências da diversidade das culturas e das sociedades humanas.

Todavia, mudanças sistêmicas nas sociedades contemporâneas ao longo do século XX e o deslocamento progressivo do objeto da antropologia das sociedades ditas "primitivas" para as modernas sociedades complexas trouxeram novas perspectivas e desafios ao uso da imagem nas pesquisas antropológicas. Em meados do século passado a Antropologia visual preconizada como um campo de conhecimento se anuncia a partir da obra de Margaret Mead e Gregory Bateson (1942), pesquisa que inspira novas experimentações metodológicas e conceituais do uso das imagens, no caso a fotografia, para a produção do conhecimento antropológico. Em 1975, será novamente Mead quem, em um artigo clássico da disciplina, irá relativizar o lugar da escrita no processo de construção do conhecimento em Antropologia, construindo definitivamente o desafio da pesquisa com imagem visual ou sonora na produção antropológica. Contemporaneamente convivemos com as tecnologias digitais e eletrônicas e o cenário da produção científica em antropologia se volta para a extroversão planetária de dados

\footnotetext{
${ }^{1}$ Universidade Federal do Rio Grande do Sul, Brasil.

${ }^{2}$ Universidade Federal do Rio Grande do Sul e Universidade Feevale, Brasil.
} 
etnográficos, ultrapassando a comunidade de comunicação dos antropólogos, via WEB. Este percurso de produções, para o caso da antropologia visual no Brasil, implicou a estruturação desta disciplina nas instituições de ensino superior. Para esta promoção era urgente a publicação literária de estudos na área especializada seja na forma de artigos, capítulos de livros, seja na forma de periódicos e livros (organizados e integrais) que sustentassem as referências da pesquisa no âmbito da academia brasileira.

Analisar a trajetória de produção de um campo disciplinar como da antropologia visual para o caso do Brasil, nos insere, assim, no desafio epistolar de arguir sobre as origens de um campo conceitual no interior do encadeamento de sentidos de uma "comunidade de interpretação" (Cardoso de Oliveira, 1995). Importa considerar a gênese da disciplina a partir de produções teóricas e conceituais que teceram o lugar da imagem, do visual e da visualidade na prática da pesquisa de antropólogos(as) brasileiros(as) tanto quanto vale reconhecer os movimentos da disciplina que a situam hoje na interface com o sistema informatizado. Um esforço intelectual que não pode prescindir de uma reflexão interpretativa das produções disciplinares na área a partir de uma vigilância epistemológica que reivindica uma constante posição crítica e dialógica a respeito do impacto dos paradigmas modernos na Antropologia brasileira.

Nossa intenção na escritura deste artigo é de atingir uma comunidade interpretativa atenta às "produções discursivas" (históricas ou contextuais) que deram procedência a linha de pesquisa de Antropologia visual no Brasil, propondo-nos pensar as múltiplas e diversas experiências com o ensino e a pesquisa antropológica com e através das imagens como fenômeno que integram as "práxis institucionais" (De Certeau, 2002) das quais elas resultam.

Por um lado, podemos perscrutar, no tempo presente, tais produções a partir de diversos levantamentos das produções realizadas por antropólogos(as) brasileiros(as) que utilizaram os recursos audiovisuais em suas investigações de campo etnográfico. Por outro, podemos seguir o inventário de festivais de documentários etnográficos, de exposições fotográficas, do uso dos recursos audiovisuais como novas formas de escritas etnográficas, de estruturas curriculares de ensino onde a disciplina de Antropologia visual se faz presente. Inventariamos a produção de artigos e livros, além de importantes coleções de revistas especializadas que deram suporte teóricometodológico ao ensino e à pesquisa, além de permitir a reciprocidade e o diálogo frutífero com as redes internacionais de pesquisa em Antropologia visual. 
Neste percurso intelectual tratamos de tornar manifesto os "campos semânticos" (De Certeau, 1996) em torno do qual podemos delinear um discurso da prática da Antropologia visual no Brasil, sob a dinâmica de núcleos de pesquisa e sob a forma de uma bibliografia especializada. Principalmente no momento em que a maioria da produção deste campo de conhecimento passa a optar, cada vez mais, por periódicos eletrônicos como meio de divulgação científica, não só pela agilidade da circulação da informação, mas pelo barateamento dos custos de impressão de imagens, além da facilidade de reprodução e circulação de sua produção intelectual em portais, blogs, etc.

Da mesma forma, ao reunir a produção bibliográfica que configura a consolidação de uma "comunidade interpretativa" no Brasil para a produção de saberes e fazeres na área da antropologia visual se percebe uma forte correlação entre a produção intelectual sob a forma de artigos e livros e a organização de eventos científicos sobre o tema assim como a constituição da disciplina de Antropologia Visual no interior de inúmeros programas de pós-graduação do país. Para o caso deste artigo, limitamo-nos às produções que avaliamos como de maior circulação entre os pesquisadores e com expressiva frequência de citação nos programas curriculares de ensino, dissertações e teses de antropologia.

\section{O campo interpretativo da Antropologia visual no Brasil}

Iniciamos nosso percurso com a constatação de que, no Brasil, as associações científicas tais como Associação Nacional de Pós-Graduação e Pesquisa em Ciências Sociais/ANPOCS (com reuniões anuais) e a Associação Brasileira de Antropologia/ABA (com reuniões bianuais) tornaram-se arenas de ação de pesquisadores que trabalham com imagens com o objetivo de criação de uma política científica específica para área da Antropologia visual. Ambas as associações tiveram um papel fundamental de reconhecimento de que os pesquisadores que atuavam na área da produção audiovisual formavam uma "comunidade de interpretação" com demandas de recursos e subsídios junto às organizações de fomento ao desenvolvimento de pesquisas 
e ensino ${ }^{3}$ em programas de pós-graduação tanto quanto em organismos nãogovernamentais ${ }^{4}$.

Os encontros regulares de pesquisadores brasileiros atuando nesta área foi um dos fenômenos responsáveis pela formação de uma ativa rede de antropólogos(as) que tem por característica, ainda nos dias atuais, uma intensa troca intelectual, seja sob a forma de permutas de produções entre núcleos, laboratórios e centros de pesquisa, seja de intercâmbio em eventos científicos, defesas de dissertações e teses. Compartilhando uma "teoria vivida" (Peirano, 2006), a Antropologia visual no Brasil se conformou num campo intenso de diálogo entre os pesquisadores assim como de circulação de "fatos etnográficos" por eles registrados.

Podemos assinalar a década de 1980 como um momento privilegiado de abertura da pesquisa antropológica para a produção audiovisual do país, com repercussões nas formas de construção de conhecimento em Antropologia. Neste período emergem, nos centros de pesquisa e programas de pós-graduação brasileiros, os primeiros cursos universitários voltados à prática da pesquisa etnográfica com instrumentos audiovisuais. Dentre os cursos propostos nos sistemas curriculares, destaca-se a oficina desenvolvida em 1982 pela antropóloga Ana Luiza Fayet em formação na Universidade de Brasília, fruto de sua pesquisa mestrado sobre a vida e trabalho de catadores de lixo da periferia de Brasília, do qual resultou a produção do audiovisual em coautoria com o fotógrafo e antropólogo Milton Guran. Na sequência, em 1984, é desenvolvido o curso de especialização Recursos Audiovisuais em Etnologia, coordenado por Maria Eugênia Brandão A. Nunes (Universidade Católica de Goiás/UCG), que constituía numa revisitação da obra de antropólogos precursores que, no Brasil, utilizaram o instrumento fotográfico ou fílmico em suas pesquisas de campo, dentre eles a obra de Wolf Jesco von Puttkamer (1919-1994). São ações embrionárias que lançam as primeiras provocações para o campo de produção em antropologia visual que começa a emergir.

A expansão da disciplina está associada a demanda, naquela conjuntura, de jovens estudantes por esta linha de pesquisa nos processos de formação institucionais que estimula a criação de centros de pesquisa em antropologia visual. Seus

\footnotetext{
${ }^{3}$ Especialmente a Coordenação de Aperfeiçoamento do Ensino Superior/CAPES e o Conselho Nacional para o Desenvolvimento Cientifico/CNPq.

${ }^{4} \mathrm{O}$ caso do Centro do Trabalho Indigenista/CTI (São Paulo) foi exemplar neste sentido. O CTI foi criado em 1979 e abrigará um dos mais importantes projetos de produção audiovisual junto aos grupos indígenas no Brasil, o projeto Vídeo nas Aldeias de 1986. Ver mais em http://www.videonasaldeias.org.br/2009/index.php
} 
pesquisadores se reúnem nos fóruns anuais como o da Reunião Anual da ANPOCS e da Reunião Brasileira de Antropologia (RBA).

Em 1992, na XXI Reunião Anual da ANPOCS, esta associação abre espaço para a iniciativa de organização de uma mostra de vídeos etnográficos acompanhada de debates preferencialmente na presença de seus diretores e equipe participante. A iniciativa que projeta a formação de uma rede de pesquisadores na área audiovisual no interior das ciências sociais do Brasil e que estimula a emergência de uma rede de pesquisadores de forma mais contínua teve a liderança das pesquisadoras Bela FeldmanBianco (Universidade Estadual de Campinas/UNICAMP, SP) e Ana Galano (Universidade Federal do Rio de Janeiro), atuação que registramos como pioneira nos esforços de promover, de uma forma mais abrangente e duradoura, a produção sistemática de pesquisa audiovisual nos cursos de antropologia. Neste processo organizam, em 1993, o seminário temático "Ciências Sociais \& Imagem”, ocasião em que inauguram um Grupo de Trabalho sobre "Usos da imagem nas Ciências Sociais". Na trilha da popularização da pesquisa com imagens no campo das ciências sociais, o GT se reapresenta nas reuniões da ANPOCS. De 1994 a 1996 segue sob a coordenação de Bela Feldman-Bianco e Ana Maria Galano. Para consolidar a continuidade do debate, organizam a formação da rede de antropologia visual em uma reunião da ANPOCS em 1996. Amplia-se a abrangência da rede brasileira de antropólogos audiovisuais, agora com a participação de pesquisadoras das mais diversas universidades. Registra-se o esforço do pesquisador Mauro Koury (1997) da Universidade Federal da Paraíba, UFPB, para elaborar uma enquete sobre a produção audiovisual na pesquisa social brasileira. No material publicado pela Anpocs e UFPB, pode-se constatar algumas experiências de ensino já consolidadas como de Sylvia Caiuby Novaes que desenvolvia um curso de antropologia visual na USP, incentivando a formação de uma geração que hoje ocupa cargos de pesquisador e professorado em antropologia visual em São Paulo e outros estados.

Os pesquisadores desta rede de antropólogos, sociólogos, cientistas sociais e cientistas políticos passaram a compor a Comissão de Imagem e Som da ANPOCS, com a responsabilidade de articular propostas temáticas de mesas redondas e de estimular a participação sistemática dos membros associados em grupos de trabalho de produção audiovisual em ciências sociais, de mostras de filmes documentários, de exposições fotográficas e de sessões de pesquisas sonoras. 
No âmbito da Reunião Brasileira de Antropologia (RBA), citemos a XIX edição do evento em Niterói, em 1994, na despedida da gestão do presidente Silvio Coelho dos Santos (da UFSC), ocasião em que foi organizado uma mesa de debates sobre questões éticas na pesquisa audiovisual em antropologia do qual participaram Patrícia MonteMór, Renato Athias, Cornelia Eckert, Clarice Peixoto, Etienne Samain entre outros. Mas foi no evento realizado em Salvador em 1996 e organizado na presidência do antropólogo João Pacheco de Oliveira Filho (da UFRJ), que foi promovido o primeiro prêmio para vídeo etnográfico alcunhado de Prêmio Pierre Verger. Novamente o esforço de agenciamento da antropologia visual está sob a maestria de Bela FeldmanBianco apoiada pelo organizador do evento, o antropólogo Carlos Caroso. Formou também a comissão de avaliação o antropólogo e cineasta francês Marc Henri Piault (CNRS/França). O primeiro documentário premiado se intitulava "Yãkwá, O Banquete dos Espíritos" sob a direção da antropóloga Virgínia Valadão (1952-1998), produzido no âmbito do projeto "Vídeo nas Aldeias", na época vinculado ao Centro de Trabalho de Indigenista em São Paulo. Naquele momento, integram a programação inúmeras atividades sobre o tema dos usos dos recursos audiovisuais para a produção do conhecimento em Antropologia, sob a forma de Grupo de Trabalho coordenado por Clarice Peixoto e Cornelia Eckert, Mesa Redonda, Oficina de vídeo etnográfico, Mostra Livre de Fotografias e Mostra de Vídeos. O troféu do prêmio só foi criado na gestão de Miriam Pillar Grossi por andamento da XXV RBA em Goiânia (GO), ocasião em que a presidente da comissão do Prêmio Pierre Verger, a antropóloga Ana Luiza Carvalho da Rocha, apresentou a estatueta Fatumbi criada pelo escultor Nico Rocha (Porto Alegre, RS). Importante referir, que nesta oportunidade o Consulado da França apoiou o evento, permitindo uma maior visibilidade ao prêmio, e a presença de antropólogos cineastas franceses no debate sobre a produção de antropologia visual no Brasil.

Dois livros organizados na forma de coletânea divulgam a produção destes momentos efervescentes de debate em antropologia visual. A publicação de "Desafios da Imagem: fotografia, iconografia e vídeo nas ciências sociais" é organizada por Bela Feldman-Bianco e por Míriam Moreira Leite (1998). Esta obra tem, em sua apresentação, uma homenagem para a ANPOCS como instituição que cria um importante espaço acadêmico de circulação de conhecimento da pesquisa com imagens, em especial ao apoio de Alícia Abreu e Flávio Pierucci, então membros da diretoria. A obra também aponta outras mostras de vídeos e de fotografias, jornadas e seminários 
que foram fundamentais para consolidação da Antropologia visual com área de produção de conhecimento. Outro livro que reúne trabalhos desta geração é "Imagem em foco", organizado por Cornelia Eckert e Patrícia Monte-Mór (1999), reunindo pesquisas apresentadas no Grupo de Trabalho de Antropologia Visual desenvolvido na XXI Reunião Brasileira de Antropologia em Vitória (ES) na gestão da presidente Mariza Correa. Neste livro a antropóloga e cineasta Virgínia Valadão relata o processo de construção do seu documentário premiado.

Também nesta Associação se institucionaliza o Comitê de Antropologia Visual da Associação Brasileira de Antropologia criado na gestão do presidente Ruben George Oliven (da UFRGS) que responde favoravelmente a reivindicação oficialmente apresentada na Assembleia da classe em 1999 durante o evento da ANPOCS, em Caxambu, MG, tendo por primeira coordenadora a antropóloga Patrícia Monte-Mór (2000-2002), Cornelia Eckert (2002-2004), Renato Athias e Carmen Rial (2004-2006), Renato Athias (2006-2008), Clarice Peixoto (2008-2010), Claudia Turra Magni (20102012), Paula Morgado (2012-2014) e Marcos Alexandre dos Santos Albuquerque (2014-2016).

\section{A consolidação de um campo científico}

Atualmente as produções com imagens conformam, no Brasil, um campo científico de envergadura. Nos programas de Mestrado e Doutorado em Antropologia proliferam os cursos de antropologia visual, antropologia audiovisual, antropologia fílmica, fotoetnografia (Achutti, 1997), antropologia e imagem visual e sonora, etc. O reconhecimento da pesquisa e do ensino da Antropologia visual no Brasil atinge um grau de solidez no momento em que este campo de conhecimento, via mobilização dos pesquisadores da área, passa a integrar oficialmente a política científica de fomento à pesquisa e ensino (Coordenação de Aperfeiçoamento de Pessoal de Nível Superior, CAPES e Conselho Nacional de Desenvolvimento Científico e Tecnológico, CNPq), sendo o movimento acompanhado de uma produção de artigos e livros, os quais foram fundamentais para a sua consolidação nos moldes de uma rede interdisciplinar de pesquisadores e professores atuantes na área. 
Neste percurso as primeiras publicações eram recebidas com ansiedade pelos professores de antropologia visual dado a carência de bibliografia para o desenvolvimento de programas de aulas. Destacamos a publicação "Caderno de textos, Antropologia Visual” (1987) contendo os debates ocorridos no II Festival LatinoAmericano de Cinema dos Povos Indígenas, organizado por Cláudia Meneses (Museu do Índio/RJ), por Patrícia Monte-Mór (UERJ) e por Milton Guran (UnB). Participaram da publicação professores e pesquisadores do Programa de Pós-Graduação em Multimídia/UNICAMP, dentre eles dois expoentes da pesquisa na interface da antropologia e fotografia no país, Etienne Samain e Fernando de Tacca. A publicação aborda os desafios do campo da pesquisa em Antropologia visual no Brasil, com o foco no tratamento da questão indígena no contexto nacional apontando as diferenças, por exemplo, do uso de fotografias em trabalhos antropológicos e em documentários com a finalidade testemunhal e ilustrativa.

Acompanhando as primeiras iniciativas de publicações versando sobre a pesquisa antropológica com imagem, surgem outras dedicadas ao debate em torno da pesquisa em acervos fotográficos e fílmicos para o campo dos estudos pioneiros de antropologia e etnologia no Brasil. Como parte dessa linhagem editorial, estão os estudos sobre os usos das fotografias de acervos incorporados à pesquisa científica, e dentro dela, destacamos o livro de Míriam Moreira Leite (1993) da Universidade de São Paulo, como paradigmático sobre o tema da memória coletiva no Brasil. A obra trata das contribuições dos estudos dos álbuns de famílias de imigrantes de várias origens vindos para São Paulo (1880-1930).

No diálogo com as novas tendências do mercado editorial apontam as primeiras publicações dos antropólogos refletindo sobre as contribuições de obras fílmicas como a de Luiz Thomaz Reis, militar que atuou projeto de pacificação do Marechal Rondon junto as sociedades indígenas brasileiras na década 1890, para o campo da produção antropológica audiovisual no Brasil, e que foi tema da tese de doutoramento de Fernando de Tacca (2001). Na mesma perspectiva importantes publicações colocam em destaque a produção de fotografia de precursores de estudos etnológicos e populações afro-brasileiras como as obras de Claude Lévi-Strauss (1994) sobre os Bororo no Brasil, Darcy Ribeiro (1996), Luiz de Castro Faria (2001) e Pierre Verger (2002, 2002a). 


\section{Internacionalização da antropologia visual brasileira}

Concomitantemente a consolidação do campo intelectual da Antropologia visual no Brasil ocorria o seu processo de inserção no cenário internacional, com a atuação expressiva de Patrícia Monte-Mór e José Inácio Parente (Interior Produções Ltda.), em 1993, a frente da organização da 1a Mostra Internacional do Filme Etnográfico, reunindo no Rio de Janeiro nomes expressivos da produção nacional e internacional do cinema etnográfico (Brasil, Estados Unidos, França, Inglaterra, Alemanha, Argentina, Canadá, Cuba, Japão e Peru, entre outros).

Com inspiração nos festivais tais como o Bilan du film ethnographique/França, dirigido por Jean Rouch, o Margaret Mead film and vídeo festival e o Native american film festival/EUA, e seguindo os passos do gênero francês documentaire sur le grand écran, foi destaque da $1^{\mathrm{a}}$ Mostra as produções pioneiras de Luiz Thomaz Reis e do projeto "Vídeo nas Aldeias" da CTI (São Paulo) de Vincent Carelli, Dominique Gallois e Virgínia Valadão, ao lado dos filmes etnográficos de Robert Flaherty (Estados Unidos), Marcel Griaule (França), John Grierson (Inglaterra), Jean Rouch (França), Robert Gardner (Estados Unidos), Tim Ash (Estados Unidos), John Marshall (Estados Unidos) e David Macdougall (Estados Unidos) entre outros, etc.

Além do tradicional catálogo, esta Mostra dá origem a uma publicação organizada por Patrícia Monte-Mór e José Inácio Parente (1994), reunindo os principais tópicos debatidos durante os seminários que compunham a programação do festival. A partir da experiência bem sucedida, novas edições do festival prosseguem, até os dias atuais, sempre reunindo filmes etnográficos clássicos e contemporâneos.

Em 1995, podemos destacar o lançamento do periódico científico, "Cadernos de Antropologia e Imagem”, organizado por Patrícia Monte-Mór e Clarice Peixoto (ambas da UERJ), contendo importantes artigos de antropólogos visuais brasileiros e de pesquisadores e profissionais da área da produção audiovisual do cenário internacional, traduzidos para a língua portuguesa. Um periódico que se teve um importante papel de promover a circulação da produção de conhecimento na área da Antropologia Visual fomentando de forma efetiva o acesso à bibliografia especializada no interior de cursos de graduação e de programas de pós-graduação brasileiros. Material igualmente riquíssimo para os pesquisadores envolvidos com o estudo temático em núcleos de pesquisa em antropologia audiovisual no país em São Paulo, no Rio de Janeiro, em 
Porto Alegre, em Recife, em Florianópolis, em Natal, em Goiânia, em Fortaleza e, mais recentemente, em Brasília, em Pelotas, em Belém, em Manaus, em Salvador, em Niterói, etc.

As jornadas que reúnem latino-americanos igualmente promovem o debate da rede de pesquisadores. Primeiramente citamos a iniciativa da 1a e a 2 a Jornadas de Antropologia Visual, realizadas em Porto Alegre/RS, respectivamente nos anos de 1992 e de 1994. Mas já a partir de 1995 as jornadas se transformam em GTs, Simpósios, Mesas, Exposições e Mostras (vídeo, som, multimídia) nas Reuniões de Antropologia do Mercosul (RAM). Assim desde a 1a Reunião de Antropologia Mercosul/RAM, realizada em Tramandaí/Rio Grande do Sul/Brasil e na 2a Reunião de Antropologia Mercosul/RAM, que transcorreu em Piriápolis/Uruguai, as jornadas de antropologia visual são uma constante nestes eventos internacionais (no Brasil na UFRGS, UFSC e UFPR), no Uruguai e na Argentina. Mais recentemente o mesmo processo é dinamizado na Reunião Equatorial de Antropologia, em sua quarta edição, realizadas em universidades nas regiões norte e nordeste do Brasil.

\section{Do circuito acadêmico para o circuito das livrarias}

As fecundas "interlocuções transdisciplinares" no que se refere ao uso de linguagens visuais na pesquisa em ciências sociais ocorridas durante os grupos de trabalho nos eventos nacionais resultam em frutíferas publicações. Nos Programas de Pós-Graduação em Antropologia Social, a linha de pesquisa de antropologia visual passa a receber incentivos nas estruturas curriculares. O campo da antropologia visual se consolida com os inúmeros núcleos de antropologia visual que despontam como importantes centros de estudos sobre os usos dos recursos audiovisuais na pesquisa antropológica do país e, em seu âmbito, as inúmeras publicações. Pioneiro no Brasil, o Laboratório de Imagem e Som em Antropologia (LISA), é fundado, em 1991, por Sylvia Caiuby Novaes no contexto da Universidade de São Paulo. No Laboratório de Imagem e Som da USP, temos a publicação de Sylvia Caiuby Novaes (1993) sobre sua experiência de trabalho de campo com as sociedades brasileiras, especialmente os Bororo (coletivo indígena que habita o estado do Mato Grosso, no Brasil), abordando o contato de tais populações com outras sociedades e as mudanças socioculturais daí decorrentes. Mas é a produção do vídeo Casamento Paquistanês, que encontramos as 
provocações da cineasta para filmar a pesquisa etnográfica. Esta produção está relacionado a formação do GRAVI - o Grupo de Antropologia Visual na USP.

No Rio Grande do Sul, o Núcleo de Antropologia Visual (NAVISUAL) organizado em 1992 como projeto do Laboratório de Antropologia Social, é reconhecido em ata pelo Departamento de Antropologia como núcleo de antropologia visual em 1994, desde então coordenado por Cornelia Eckert. Mas foi um entusiasta aluno de Ciências Sociais, o cineasta Nuno Godolphim, que reivindicava aos professores, a organização de um núcleo de pesquisa sistemática no campo da antropologia visual. Inserido em uma rede de produção de filmes e fotografia na cidade, articulou a vinda de fotógrafos antropólogos e cineastas antropólogos para desenvolverem cursos de formação e neste âmbito construir o Núcleo de Antropologia Visual. Como fruto dos debates transcorridos ao longo de jornadas de Antropologia Visual, vários papers são publicados em um volume da Revista Horizontes Antropológicos, do PPGAS/UFRGS dedicado ao tema da Antropologia visual (Eckert e Godolphim, 1995) contendo artigos de uma nova geração de pesquisadores. Na linha editorial mencionamos o livro organizado por Luiz Eduardo Achutti (1998), a partir de um simpósio promovido pela Secretaria Municipal de Cultura de Porto Alegre/RS, cujo tema foi o ato fotográfico, e que trouxe importantes reflexões de várias gerações de fotógrafos, antropólogos, sociólogos e comunicólogos sobre o uso da fotografia na prática das ciências sociais.

A tradição de vincular evento científico em antropologia visual a alguma publicação impressa ou eletrônica, passa ser uma assertiva verdadeira. Mas é importante considerar que o diálogo não é restrito a uma comunidade de antropólogos. Antes a pesquisa com imagem se embasa cada vez mais em uma interdisciplinaridade. Várias publicações testemunham esta onda de trocas como uma linha editorial eficaz. Neste campo, destacamos a coletânea organizada por Etienne Samain (1998), reunindo 26 ensaios de profissionais de diferentes áreas de conhecimento em seus esforços por decifrar os múltiplos significados que o uso da fotografia na tradição da pesquisa antropológica desde suas origens.

A política editorial de dissertações e teses defendidas nos programas de pósgraduação brasileiros teve, sem dúvida, um papel significativo na divulgação de trabalhos com pesquisas etnográficas e etnológicas com produção de imagens visuais e sonoras. No Programa de Pós-Graduação em Antropologia Social (UFRGS), citamos a 
primeira dissertação do Programa, de Ondina Fachel Leal (1986), contendo fotografias como parte integrante das interpretações dos dados de campo. O trabalho traz um capítulo onde as imagens captadas pela etnógrafa dialogam com suas interpretações acerca do lugar da televisão no mundo dos objetos dos aficionados pela "novela das oito" nas diversas camadas sociais, em Porto Alegre/RS/Brasil, publicada, no mesmo ano, sob a forma de livro.

No nordeste do Brasil, através de uma iniciativa da Fundação Waldemar de Alcântara, com apoio da Secretaria da Cultura e Desportos do Ceará, na coleção Teses cearenses, é publicada a obra de Eymard Porto (1993), resultado de dissertação orientada por Bela Feldman-Bianco (professora na UNICAMP/SP).

Anos mais tarde, seguindo a mesma trilha de sua orientadora Ondina Fachel Leal, Luiz Eduardo Achutti (1997) defende uma dissertação em Antropologia Visual junto ao PPGAS/UFRGS. Com o estudo fotoetnográfico sobre cotidiano, lixo e trabalho em uma vila de reciclagem em Porto Alegre, cria na instituição uma nova tendência de pesquisa onde as imagens visuais e sonoras integram a pesquisa acadêmica em Antropologia Social.

No campo do pensamento antropológico, o expressivo aumento de publicações acadêmicas sob o prisma da produção audiovisual acompanha, nas últimas décadas do século passado, as preocupações dos investigadores com os temas da memória vivida dos grupos sociais e das transformações que atingiam a sociedade brasileira: os processos de metropolização, as transformações do espaço público, etc. Um exemplo desta tendência é o caso da publicação de Antônio A. Arantes (2000) professor na UNICAMP/SP. O autor aborda a construção social do espaço público no contexto paulistano, sob o prisma de uma reflexão sobre a preservação do patrimônio cultural e da formação da nação.

Em 2002, Rosane de Andrade sob a orientação de Carmen Junqueira (Pontifícia Universidade Católica de São Paulo) apresenta uma tese que tem por objeto de estudo a obra do antropólogo francês Pierre Verger e sua produção fotográfica no Brasil. Outro exemplo bem sucedido de publicação de trabalho universitário na área de Antropologia visual é a obra de André Alves (2004), de excelente qualidade gráfica, produto da dissertação defendida na UNICAMP/SP, sob a orientação de Etienne Samain e que, inspirado na tradição batesoniana de construção de pranchas fotográficas sequenciais e 
estruturais, retrata a vida e trabalho dos catadores de caranguejos nos mangues próximos a Vitória, capital do Espírito Santo.

A publicação de teses e dissertação fortalece definitivamente o campo intelectual da antropologia visual. Crescem as obras resultantes de teses de doutorado defendidas no exterior como de Milton Guran (2000) na EHESS/França, Clarice Peixoto (2000) defendida na EHESS/França, Luiz Eduardo Achutti (2004) defendida na Universidade Paris 7/França e no Brasil, Fraya Frehse (2005) na USP e Gabriel Alvarez (2009) na UnB. Frehse tem por base um acervo fotográfico sobre as ruas de São Paulo e Alvarez, com pesquisa em etnologia, problematiza em sua tese a pesquisa com recursos audiovisuais como metodologia de estudo e traz em anexo à publicação dois CDs contendo os filmes realizados durante seu trabalho de campo. A nova geração formada por Sylvia Caiuby Novaes, assumia os desafios da líder e com forte apoio da FAPESP, inúmeras produções passam a ter destaque com as pesquisas de Rose Gitirana Hikiji, Priscilla Ermel, Carolina Caffé, Ana Lucia Ferraz, Andréa Barbosa e Francirosy Ferreira, Edgar Teodoro da Cunha, Paula Morgado, Renato Sztutman.

\section{Consolidação de um campo de produção}

A chegada do novo século aporta uma novidade de política científica importante: a já citada formação do Grupo de Trabalho Antropologia Visual da Associação Brasileira de Antropologia/ABA. Após o sucesso do Prêmio Pierre Verger em Vídeo Etnográfico foi lançado, durante a Reunião Brasileira de Antropologia em 2002, a primeira edição do Concurso de Ensaio Fotográficos baseados em pesquisas etnográficas ${ }^{5}$. Em 2012 o grupo recebe o reconhecimento do papel efetivo desta rede de pesquisadores, doravante organizados em um Comitê de Antropologia Visual (CAV).

Definitivamente consolidada como campo de investigação científica, a Antropologia visual será uma tendência de linha de pesquisa na maioria dos Programas de Pós-Graduação em Antropologia ou em Ciências Sociais. Em São Paulo o grupo do LISA e GRAVI, com os pesquisadores já citados, concentram uma importante liderança de produção. Esta liderança é importante para incentivar aos demais núcleos participar de eventos com nomes de destaque internacional. As entrevistas filmadas com Jean Rouch e David McDougall, são exemplos deste mérito. Em Santa Catarina se consolida

\footnotetext{
5 Para outras informações sobre a ABA recorrer a www.abant.org.br e para conhecer o histórico do comitê e sua atuação sugerimos o blog http://antropologiavisualaba.blogspot.de/
} 
o Núcleo de Antropologia Visual/NAVI (Universidade Federal de Santa Catarina, UFSC), criado em 1998, coordenado por Carmen Silvia Rial. A mesma tendência encontramos nas regiões norte, nordeste e centro-oeste. Citemos entre outros a iniciativa do Laboratório de Antropologia Visual/AVAL (Universidade Federal de Alagoas/UFAL) que promove o Encontro de Antropologia Visual, sob a coordenação de Silvia Martins, Siloé Amorim e Fernanda Rechenberg, no Laboratório de Antropologia e Imagem/LAI (Universidade Federal do Ceará, UFC) que promove o Ciclo Internacional de Diálogos em Antropologia e Imagem sob a coordenação de Peregrina Campelo. Em Recife atua o Laboratório de Antropologia Visual do Núcleo Imagem e Som \& Ciências Humanas (Universidade Federal de Pernambuco, UFPE) que tem a liderança de Renato Athias. Esta equipe é responsável pela promoção do Festival anual do Filme Etnográfico do Recife. A cidade de Rio Tinto (Universidade Federal da Paraíba, UFPB) tem sua história e tradição pesquisada pelo núcleo de antropologia visual coordenado João Martinho Braga de Mendonça e, em Natal, o Núcleo de Antropologia Visual/NAVIS é coordenado por Lisabete Coradini (Universidade Federal do Rio Grande do Norte, UFRN). Mais recentemente foram criados novos núcleos. Em 2001, em Brasília (Universidade de Brasília, UnB) a pesquisa com imagens é empenhado pelo Laboratório de Imagens e Registro de Interações Sociais/IRIS, em Goiânia (Universidade Federal de Goiás, UFG) o núcleo de Antropologia Visual é coordenado por Gabriel Alvarez e em Niterói (Universidade Federal Fluminense, UFF) o grupo de antropologia visual é coordenado por Ana Lúcia Ferraz. Outros Programas, mesmo sem um núcleo específico na área promovem eventos anuais como em Belo Horizonte (MG) em que Ruben Caixeta de Queiroz (UFMG) é co-fundador e coorganizador do FORUMDOC.BH (Festival do Filme Documentário e Etnográfico).

Acompanhando esta tendência de organização de rede de antropólogos visuais em núcleos e grupos, os debates acadêmicos estimulam cada vez mais a publicação de coletâneas e estudos sobre temas diversos, entre as quais se destacam as publicações organizadas respectivamente por Mauro Koury (2001) e Sylvia Caiuby Novaes, Andréa Barbosa; Edgar Teodoro da Cunha; Florencia Ferrari; Renato Sztutman; Rose Satiko Gitirana Hikiji (2004), e a coletânea Imagem e Conhecimento (2009), organizada por Andrea Barbosa, Edgar Cunha e Rose Satiko Hikiji reunindo os resultados dos últimos anos de pesquisas com imagens em vários centros e núcleos de universidades do país. $\mathrm{Na}$ ocasião, uma das motivações que conduzia ao debate interno da rede referia-se as 
modalidades da produção audiovisual no âmbito dos Programas de pós-graduação. A discussão se encaminha, em 2004, para a realização de um seminário temático na ANPOCS, do qual resulta a publicação organizada por José de Souza Martins/USP, Cornelia Eckert/UFRGS e Sylvia Caiuby Novaes/USP (2005).

Da mesma forma, a nova rede de pesquisadores audiovisuais avança com estudos que tratam de uma revisita a obra dos pais fundadores a pesquisa antropológica com imagens. Inaugurando esta perspectiva temos a publicação de artigos de Etienne Samain na já citada revista Horizontes Antropológicos tanto quanto no já citado livro em coautoria com André Alves: nestes, Bronislaw Malinowski, Margareth Mead e Gregory Bateson são retomados em suas produções imagéticas. Outros seguem esta tendência como o livro de autoria de Edgar Teodoro da Cunha e de Andréa Barbosa (2006), revisitando os momentos inaugurais da formação do campo da pesquisa em Antropologia como disciplina em seus laços com a história do nascimento do cinema (Robert Flaherty, Vertov, etc.) no esforço de situá-las no interior das experiências contemporâneas no uso dos recursos audiovisuais na pesquisa etnográfica (entre eles, Jean Rouch e David Macdougall).

Prosseguindo nesta perspectiva, destacamos o trabalho de Marco Antônio Gonçalves (2008) da UFRJ sobre a obra de Jean Rouch, e, posteriormente, do mesmo autor em companhia de Scott Head (2009), tendo como inspiração a obra de Marilyn Strathern (1990) sobre a metáfora do corpo na prática etnográfica e em suas estratégias narrativas. No mesmo ano aparece a publicação organizada por Andréa Barbosa, Rose S. G. Hijiki e Edgar T. Cunha (2009) composto por uma coletânea de artigos de pesquisadores brasileiros e estrangeiros interessados nas aproximações entre a pesquisa com imagens na área da produção de conhecimento das ciências sociais.

No campo da produção fotográfica, aprofundam-se os estudos sobre o lugar que ela ocupa no interior de uma civilização de consumo de imagens, em particular, nas publicações impressas. Entre os exemplos de revisita crítica ao mercado das imagens no Brasil encontramos a publicação de Fernando de Tacca (2009) que aborda as reportagens fotográficas de jornalistas que criaram um contexto imaginário em torno da prática do culto afro brasileiro. Outra expressão desta tendência foi o volume especial da Revista de Estudos Amazônicos (2007) que publicou os resultados de trabalhos apresentados e discutidos na I Mostra Amazônica de Filme Etnográfico (2006), sob a organização de Selda Vale da Costa (Universidade Federal da Amazônia/UFAM) em 
colaboração com o Núcleo de Antropologia Visual/NAVI (UFSC), dedicado a reflexão acerca da representação da região da Amazônia no cinema documentário e etnográfico.

\section{A expansão das produções para as redes digitais e eletrônicas}

A política de expansão do sistema web e o incentivo político das instituições financiadas de pesquisa no Brasil para publicação de revistas eletrônicas trouxe uma nova adoção estilística na produção de periódicos destinados a ampla divulgação e circulação da produção audiovisual no Brasil

$\mathrm{Na}$ área das publicações eletrônicas, destacam-se duas revistas eletrônicas com mais de 10 anos de tradição de divulgação da produção intelectual nacional e internacional na área da Antropologia visual. A primeira é a Revista Studium/UNICAMP, criada em 1999, sob a coordenação Fernando de Tacca, junto ao Laboratório de Media e Tecnologias de Comunicação/ UNICAMP. A segunda publicação de referência é a Revista Eletrônica Iluminuras, do Banco de Imagens e Efeitos Visuais/BIEV, do PPGAS/UFRGS, criada em 2000, por Ana Luiza Carvalho da Rocha e Cornelia Eckert.

Importante referendar que a Revista Vivência que atende o Programa de PósGraduação em Antropologia/UFRN, apresenta um volume organizado por Lisabete Coradini (2001), com predominância de artigos refletindo sobre o uso do vídeo e de imagens eletrônicas na construção de narrativas visuais na pesquisa antropológica. A publicação da revista eletrônica resultou de inúmeros debates ocorridos no interior dos grupos de trabalho das reuniões bianuais da Associação Brasileira de Antropologia/ABA. Importa citar igualmente a Proa - Revista de Antropologia e Arte, editada na UNICAMP, criada em 2009 e já na sua $5^{\text {a }}$ edição: http://www.revistaproa.com.br/05/.

Com a preocupação constante com a produção audiovisual no Brasil, em 2008, a ABA, em comemoração aos 10 anos do Prêmio Pierre Verger reuniu, sob a coordenação de Claudia Turra Magni (Universidade Federal de Pelotas/UFPel) e Clarice Peixoto, todos os ensaios fotográficos e vídeos etnográficos premiados, entre 1996 e 2008, em uma única coleção composta por dezoito vídeos etnográficos (em seis DVDs) e treze ensaios fotográficos (em um CD-ROM), os quais foram disponibilizados a todos os usuários da Internet através do portal da instituição. No mesmo ano, cria-se junto ao já 
tradicional Grupo de Trabalho de Antropologia Visual/GTAV da ABA, sob a coordenação de Clarice Peixoto e tarefa desenvolvida e diagramada pelo antropólogo Rafael Devos (hoje professor na UFSC), o blog que reúne todos os núcleos, laboratórios e grupos de pesquisa do país que atuam na área, apresentando uma bibliografia básica de Antropologia Visual, com um link da produção audiovisual da associação para os usuários da Internet.

No esforço de tornar acessível as produções na área da Antropologia visual a um grande público interessado, alguns deles parceiros das investigações conduzidas pelos próprios antropólogos, surgem site como os do BIEV (www.biev.ufrgs.br) assim como o do LISA (http://www.lisa.usp.br/) que apresentam on line suas produções audiovisuais, em sua maioria com legendas em inglês. Em julho de 2014, na gestão da presidente Carmen Silvia Rial, foi criada a TV-ABA com a meta de ser uma plataforma web para a difusão das produções visuais da antropologia brasileira. A criação de uma web TV ligada a um repositório de vídeos poderá, além de disponibilizar e difundir material audiovisual já produzido pelos vários núcleos de antropologia visual. A ideia original teve o apoio do antropólogo Josep Juan Segarra (UFRGS e UFRJ). A atividade de criação contava com o apoio de outro antropólogo dedicado ao projeto, o atual coordenador do CAV Marcos Albuquerque (UFRJ).

Incorporando a blogosfera como importante espaço de divulgação dos meandros da pesquisa etnográfica, a produção audiovisual em Antropologia no Brasil segue uma tendência universal. Desta convergência de mídias para a produção de conhecimento da área audiovisual podemos mencionar blogs ligados aos usos das redes digitais e eletrônicas como parte integrante da pesquisa audiovisual contemporânea no país. O primeiro é o blog Método etnográfico, criado em 2009, por Gabriel Alvarez (UFG), dirigidos preferencialmente aos alunos em processo de aprendizagem dos usos dos recursos audiovisuais na pesquisa antropológica. O segundo é o blog do projeto Habitantes do Arroio, junto ao BIEV/UFRGS, e que emprega a blogosfera como parte de circulação e geração de dados da pesquisa sobre a memória ambiental do arroio Dilúvio na intenção de promover uma comunidade ética em defesa da sustentabilidade de usos das águas urbanas em Porto Alegre/RS. Citamos ainda o blog promovido por Renato Athias (UFPE) intitulado Imagens e Palavras que resgata importantes coleções fotográficas de antropólogos pioneiros. 
Para finalizar, em especial, mencionamos a pesquisa do Banco de Imagens e Efeitos Visuais/BIEV/UFRGS, inaugurada em 1997 como resultado da parceria de pesquisa de Ana Luiza Carvalho da Rocha (UFRGS) e Cornelia Eckert (UFRGS), e que trata da formação de acervos e da gestão eletrônica de documentos etnográficos multimídia na produção do conhecimento na área da Antropologia Visual. Uma pesquisa que, atualmente, tem resultado na-reestruturação do portal institucional assim como os sites do Projeto Memória Ambiental Porto Alegre (2012) e do Projeto Etnografias da Memória do Trabalho (2009), transformando-os em espaços de divulgação e circulação da base de dados multimídia que reúne mais de 15 anos de pesquisa sobre os itinerários urbanos, memória coletiva e formas de sociabilidade no mundo contemporâneo. Em ambos os projetos, a produção audiovisual situa-se no interior de uma nova frente de investigação para a Antropologia no Brasil, em diálogo com a tendência internacional, ou seja, a produção de narrativas etnográficas em hipermídia, no formato de DVDs interativos especialmente criados para a apresentação dos resultados das pesquisas. No âmbito do NAVISUAL, o projeto que tem sido carro chefe é de narrativas fotográficas tendo por base a pesquisa etnográfica no contexto de ruas e bairros que conhecem forte impacto de transformações urbanas. Esta pesquisa é acompanhada de uma formação sistemática em etnofotografia, videografia e pesquisa sonora em que destacamos no ano de 2010 a 2015 a dedicação dos pesquisadores Rumi Kubo (UFRGS) e os estudantes Fabrício Barreto, Jose Abalos Junior, Manoel Rocha, Yuri Rapkiewicz, Camila Braz, Aline Rochedo, Fabiela Bigossi, Roberta Simon sob a coordenação de Cornelia Eckert. Esta produção é extrovertida na Galeria Olho $\mathrm{Nu}$ e outros eventos científicos, além de divulgar os resultados de produção fotográfica e áudio visual dos alunos de Antropologia Visual, disciplina no PPGAS IFCH UFRGS e na disciplina de Antropologia Visual, no curso de Ciências Sociais na UFRGS.

Ao finalizarmos este artigo, queremos brindar o advento de mais uma revista eletrônica. Aguardamos o primeiro número de edição da revista GIS, Gesto, Imagem e Som, Revista do Departamento de antropologia da USP, do Programa de PósGraduação em Antropologia Social da Universidade de São Paulo. Vida longa para a Antropologia Visual brasileira. 


\section{Referências}

ACHUTTI, Luiz Eduardo Robson. Fotoetnografia: um estudo antropológico visual sobre cotidiano, lixo e trabalho. Porto Alegre: Tomo Editorial, 1997.

ACHUTTI, Luiz Eduardo Robson. Ensaios (sobre o) fotográfico. Porto Alegre; Secretaria Municipal da Cultura/PMPA, 1998.

ACHUTTI, Luiz Eduardo Robson, 2004. Fotoetnografia da Biblioteca Jardim. Porto Alegre: Tomo Editorial/UFRGS, 2004.

ALVAREZ, Gabriel. Sateteria Tradição e Política - Sateré Mawé. Manaus: Editora Valer/CAPES, 2009.

ALVES, André e SAMAIN, Etienne. Os argonautas do mangue precedido de Balinese character (re)visitado. Campinas: Ed. Unicamp/São Paulo: Imprensa Oficial do Estado de São Paulo, 2004.

ANDRADE, Rosane de. Fotografia e Antropologia, olhares fora-dentro. São Paulo: Editora da PUC-SP, 2002.

ARANTES, Antônio Augusto. Paisagens paulistanas. Campinas: Editora da Unicamp, 2000.

BARBOSA, Andréa e CUNHA, Edgar Teodoro da (eds.). Antropologia e Imagem. Rio de Janeiro: Jorge Zahar Editor, 2006.

BARBOSA, Andréa, CUNHA, Edgar Teodoro da, HIKIJI, Rose Satiko Gitirana (eds.). Imagem-Conhecimento. Campinas: Papirus, 2009.

BATESON, Gregory e MEAD, Margareth. Balinese Character: a photographic analysis. New York: New York Academy of Sciences, 1942.

CAIUBY Novaes, Sylvia; ECKERT, Cornelia; MARTINS José S. (eds.). $O$ imaginário e o poético nas Ciências Sociais. Bauru: EDUSC, 2005.

CAIUBY Novaes, Sylvia. Jogo de espelhos. São Paulo: EDUSP, 1993.

CAIUBY Novaes, Sylvia. 2004. Escrituras da Imagem. São Paulo, FAPESP.

CAIUBY Novaes, Sylvia. Brasil em Imagens: caminhos que marcam e antecedem a antropologia visual no Brasil. In: DIAS DUARTE, Luiz Fernando (ed.). Horizontes das Ciências Sociais no Brasil/ANPOCS. São Paulo: Instituto Ciência Hoje, Editora Barcarola e Discurso Editorial, p. 457-487, 2010.

CARDOSO DE OLIVEIRA, Roberto. Notas sobre uma estilística da antropologia. In: CARDOSO DE OLIVEIRA, Roberto e RUBEN, G. R. (eds.). Estilos de Antropologia. Campinas: Editora da Unicamp, 1995.

DE CERTEAU, Michel. A invenção do Cotidiano. Petrópolis: RJ. Ed Vozes, 1996.

DE CERTEAU, Michel. 2002. A história da escrita. Rio de Janeiro: Forense Universitária.

ECKERT, Cornelia; GODOLPHIM, Nuno. Antropologia Visual, Revista Horizontes Antropológicos, Ano 1, v. 2. Porto Alegre: Editora da UFRGS/UFRGS, 1995.

ECKERT, Cornelia; MONTE-MÓR, Patrícia. Imagem em foco, novas perspectivas em antropologia. Porto Alegre: Editora da UFRGS/UFRGS, 1999.

EVANS-PRITCHARD. Edward. Os Nuer. São Paulo: Editora Perspectiva, 1978.

FARIA, Luiz Castro. Um outro olhar, diário de expedição à Serra do Norte. Rio de Janeiro: Ed. Ouro Sobre Azul, 2005.

FELDMAN-BIANCO, Bela; MOREIRA LEITE, Miriam. Desafios da Imagem: Fotografia, Iconografia e Vídeo nas Ciências Sociais. Campinas: Papirus, 1998.

FREHSE, Fraya. O tempo das ruas na São Paulo de fins do Império. São Paulo: EDUSP, 2005.

GEERTZ, Clifford. Obras e Vidas, o Antropólogo Como Autor. Petrópolis: Vozes, 2005.

GONÇALVES, Marco Antonio; HEAD, Scott. Devires imagéticos: a etnografia, o outro e suas imagens. Rio de Janeiro: FAPERJ/ 7 letras, 2009.

GONÇALVES, Marco Antonio. O real imaginado - etnografia, cinema e surrealismo em Jean Rouch. Rio de Janeiro: Topbooks, 2008.

GURAN, Milton. Agudás: os "brasileiros" do Benim. Rio de Janeiro: Ed. Nova Fronteira/ Ed. Gama Filho, 2000. 
KOURY, Mauro. Usos da Imagem nas Ciências Sociais - Pesquisadores. Grupo interdisciplinar de Estudos e Pesquisas sobre Imagem. João Pessoa: Manufatura, 1997.

KOURY, Mauro. Imagem e Memória, ensaios em Antropologia Visual. Rio de Janeiro: Garamond, 2001.

LEAL, Ondina Fachel. A leitura social da novela das oito. Petrópolis, Vozes, 1986.

LEVI-STRAUSS, Claude. Antropologia estrutural. Rio de Janeiro: Tempo Brasileiro, 1975.

LEVI-STRAUSS, Claude. As estruturas elementares do parentesco. Petrópolis: Vozes, 1982.

LEVI-STRAUSS, Claude. Saudades do Brasil. São Paulo: Cia das Letras, 1994.

MALINOWSKI, Bronislaw. Argonautas do Pacífico Ocidental. São Paulo: Abril Cultural, 1978.

MCDOUGALL, David. Transcultural cinema. Princeton: Princeton University Press, 1998.

MEAD, Margaret. Visual Anthropology in a discipline of words. In: HOCKINGS, Paul (ed.). Principles of Visual Anthropology. Mouton: The Hague, p. 3-10, 1975.

MONTE-MÓR, Patrícia, PARENTE, José Inácio (eds). Cinema e antropologia: horizontes e caminhos da antropologia visual. Rio de Janeiro, Interior Produções, 1994.

MONTE-MÓR, Patrícia; MENESES, Claudia; GURAN, Milton (eds.). Cadernos de textos, Antropologia Visual. Rio de Janeiro: Museu do Indio, 1987.

MONTE-MÓR, Patrícia. Sobre Cadernos de Antropologia e Imagem. Revista de Estudos Históricos, Historia e Imagem, v. 2, n. 34. São Paulo, 2013. Disponível em: http://bibliotecadigital.fgv.br/ojs/index.php/reh/issue/view/301. (acesso em 26 de novembro de 2013).

MOREIRA LEITE, Miriam. Retratos de família. São Paulo: EDUSP/FAPESP, 1993.

PEIRANO, Mariza. 2006. A teoria vivida e outros ensaios de Antropologia. Rio de Janeiro: Jorge Zahar Editor, 2006.

PEIXOTO, Clarice Ehlers. Antropologia e filme etnográfico: um travelling no cenário literário da antropologia visual. BIB. Revista Brasileira de Informação Bibliográfica em Ciências Sociais, Rio de Janeiro, v. 48, p. 91-116, 1999.

PEIXOTO, Clarice Ehlers. Antropologia visual no Brasil. Cadernos de Antropologia e Imagem (UERJ), RJ, v. 1, p. 75-80, 1995.

PEIXOTO, Clarice. Envelhecimento e imagem, as fronteiras entre Paris e Rio de Janeiro. Paris: EHESS, 2000.

PORTO, Eymard. Babaquara, chefetes e cabroeira: Fortaleza no início do século XX. Fortaleza: Fundação Waldemar de Alcântara/ Secretaria da Cultura e Desportos do Ceará, 1993. RIBEIRO, Darcy. Diários Índios os Urubus-Kaapor. São Paulo: Cia das Letras, 1996.

SAMAIN, Etienne. O Fotográfico. São Paulo: Editora HUCITEC/CNPq, 2005.

SOUTY, Jerome. Pierre Fatumbi Verger: do olhar livre ao conhecimento iniciático. Rio de Janeiro, Terceiro Nome, 2012.

STRATHERN, Marilyn. 1990. The Gender of the gift. Los Angeles: University of California Press.

TACCA, Fernando de. A Imagética da Comissão Rondon. Campinas: Papirus, 2001.

TACCA, Fernando de. Luiz Thomaz Reis: Etnografias Fílmicas Estratégicas. In: TEIXEIRA, Francisco Elinaldo (ed.). Ensaios sobre o Documentário Brasileiro. São Paulo: Summus Editorial, 2004.

VERGER, Pierre. Pierre Fatumbi Verger. Salvador: Fundação Pierre Verger, 2002."

VERGER, Pierre. Orixás. Salvador: Fundação Pierre Verger, 2002a. 


\section{Webgrafia}

ALVAREZ, Gabriel, Método etnográfico (http://metodoetnografico.blogspot.com/2009/11/satereria-tradicao-e-politica-satere.html) ATHIAS, Renato, http://renatoathias.blogspot.de/

ANTROPOLOGIA VISUAL/ASSOCIAÇÃO BRASILEIRA DE ANTROPOLOGIA. Disponivel em : http://antropologiavisualaba.blogspot.com.br/. (acesso em: 25 de novembro de 2013).

ASSOCIAÇÃO BRASILEIRA DE ANTROPOLOGIA. Disponível em: http://www.portal.abant.org.br/index.php/bibliotecas/videos. (acesso em: 25 de novembro de 2013)

BANCO DE IMAGENS E EFEITOS VISUAIS /PPGAS/UFRGS. Disponível em: http://www.ufrgs.br/biev/. (acesso em: 25 de novembro de 2013)

CENTRO TRABALHO INDIGENA/CTI. Disponível em: http://www.trabalhoindigenista.org.br/default.asp. (acesso em: 25 de novembro de 2013).

CINEMATECA BRASILEIRA. Disponível em: http://www.cinemateca.gov.br/. (acesso em: 25 de novembro de 2013).

DEVOS, Rafael e ROCHA, Ana Luiza Carvalho da. Projeto Memoria ambiental Porto Alegre. Disponível em: http://www.ufrgs.br/memoriaambientalpoa/. (acesso em: 25 de novembro de 2013)

ECKERT, Cornelia. Projeto Etnografias da memória do trabalho. Disponível em: http://www.ufrgs.br/memoriasdotrabalho/. (acesso em: 25 de novembro de 2013)

FUNDAÇÃO PIERRE VERGER. Disponível em: www.pierreverger.org. (acesso em: 25 de novembro de 2013).

FUNDAÇÃO DARCY RIBEIRO. Disponível em: http://www.fundar.org.br/consulta/. (acesso em: 25 de novembro de 2013).

LABORATÓRIO DE IMAGEM E SOM/LISA/USP: Disponível em: http://www.lisa.usp.br/index.html. (acesso em: 25 de novembro de 2013)

MUSEU DE ASTRONOMIA E CIÊNCIAS AFINS/MAST-MCT. Disponível em : http://castrofaria.mast.br/. (acesso em: 25 de novembro de 2013).

REVISTA ELETRÔNICA ILUMINURAS, BIEV/UFRGS. Disponível em: http://seer.ufrgs.br/iluminuras/index. (acesso em: 25 de novembro de 2013)

REVISTA STUDIUM/UNICAMP. Disponível em:

http://www.studium.iar.unicamp.br/capas.htm. (acesso em: 25 de novembro de 2013)

REVISTA VIVÊNCIA, PPGAS/UFRN. Disponível em: http://www.periodicos.ufrn.br/vivencia/issue/archive. (acesso em: 25 de novembro de 2013)

ROCHA, Ana Luiza Carvalho da. O livro do etnógrafo. Disponível em: http://bievufrgs.blogspot.de/. (acesso em: 25 de novembro de 2013)

ROCHA, Ana Luiza Carvalho da. Habitantes do Arroio. Disponível em: http://habitantesdoarroio.blogspot.de/. (acesso em: 25 de novembro de 2013)

Recebido em: 11/11/2015.

Aprovado em: 06/04/2016. 